University of Nebraska - Lincoln

DigitalCommons@University of Nebraska - Lincoln

2006

\title{
Optimal Time Allocation in Parasitic Wasps Searching for Hosts and Food
}

Brigitte Tenhumberg

University of Nebraska - Lincoln, btenhumberg2@unl.edu

Gitta Siekmann

University of Adelaide

Michael A. Keller

University of Adelaide

Follow this and additional works at: https://digitalcommons.unl.edu/bioscifacpub

Part of the Life Sciences Commons

Tenhumberg, Brigitte; Siekmann, Gitta; and Keller, Michael A., "Optimal Time Allocation in Parasitic Wasps Searching for Hosts and Food" (2006). Faculty Publications in the Biological Sciences. 103.

https://digitalcommons.unl.edu/bioscifacpub/103

This Article is brought to you for free and open access by the Papers in the Biological Sciences at DigitalCommons@University of Nebraska - Lincoln. It has been accepted for inclusion in Faculty Publications in the Biological Sciences by an authorized administrator of DigitalCommons@University of Nebraska - Lincoln. 


\title{
Optimal Time Allocation in Parasitic Wasps Searching for Hosts and Food
}

\author{
Brigitte Tenhumberg, ${ }^{1}$ Gitta Siekmann, ${ }^{2}$ Michael A. Keller ${ }^{2}$ \\ 1. School of Natural Resources, University of Nebraska-Lincoln,Lincoln, NE, USA \\ 2. Plant and Pest Science, School of Agriculture and Wine, University of Adelaide, Australia \\ Corresponding author - B. Tenhumberg, email btenhumberg2@unl.edu \\ Present address for G. Siekmann: Institute for Plant Protection in Horticulture, \\ Federal Biological Research Centre for Agriculture and Forestry, \\ Messeweg 11-12, DE-38104 Braunschweig, Germany
}

\begin{abstract}
Many species of parasitic wasp feed on sugar sources such as nectar and honeydew in order to replenish their energy reserves and so extend their life expectancy, which is often correlated with higher reproductive success. Recent research suggests that carbohydrates are also a key component in flight fuel in such insects. The importance of sugar in fuelling locomotion suggests location of sugar-rich food may be more important in parasitoid foraging behavior than has previously been assumed. If sugar sources and hosts are separated in space, parasitoids have to allocate their time between sugar-searching and host-searching. Using a stochastic dynamic programming model we predict optimal time allocation decisions of parasitoids. Although the model was parameterized using data for Cotesia rubecula, the sensitivity analysis shows that the model predictions are applicable to many parasitoid wasp species. The key prediction of the model is that parasitoids should always search for food if energy reserves drop to low levels, even if the probability of finding food and the average food reward are small. This is in stark contrast to an alternative model proposed by Sirot and Bernstein (1996) which suggests parasitoids should never search for food if food availability is low.
\end{abstract}

The adults of numerous parasitoid species use carbohydrates for body maintenance (Gilbert and Jervis 1998, Jervis 1998), consequently they can extend their life expectancy many times by regularly replenishing their sugar reserves (Jervis and Kidd 1986, Jervis et al. 1992, 1996, Siekmann et al. 2001). Recent research (Siekmann 2002) suggests that for parasitic wasps carbohydrates are also key components in flight fuel, and that carbohydrate intake influences fitness in two ways. First, parasitoids live longer and have more time available to parasitize hosts. Second, parasitoids have more energy available for flight which might increase search area and encounter rate. Natural sugar sources in the field are mainly floral or extra-floral nectar and homopteran hon- eydew (Jervis et al. 1992, Gilbert and Jervis 1998, Jervis 1998), and are frequently found at locations other than in close proximity to host patches. So, in many cases parasitoids must either search for food or for hosts, not both simultaneously

Parasitoids need to allocate their time between hostand sugar-foraging based on the trade-off between current and future reproduction (Figure 1): host-foraging increases the likelihood of finding hosts quickly, but continuously decreases the forager's energy reserves and consequently life expectancy. On the other hand, foodforaging postpones oviposition opportunities but increases the time available to find hosts in the future through replenishment of energy reserves. The energy 


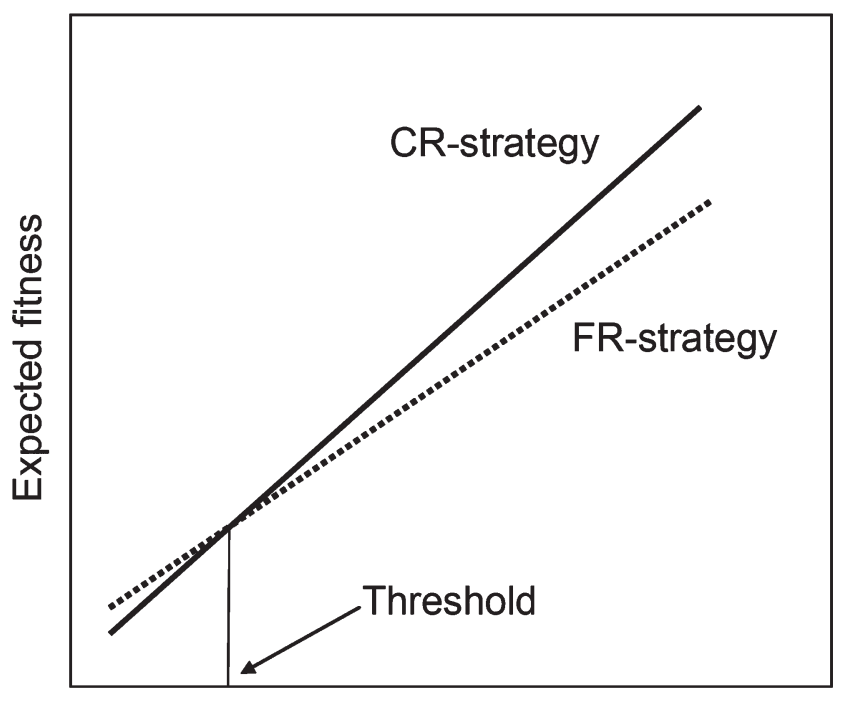

Energy reserves

Figure 1. Schematic representation of the trade-off between current (CR) and future reproduction (FR). Expected fitness decreases with energy reserves; how much it decreases depends on parasitoid's behavioral strategy. If life expectancy is high it is best to invest in current reproduction, i.e. searching for hosts. Parasitoid females should switch their behavioral strategy when both line cross, because at low energy reserves investing in future reproduction (i.e. searching for food) results in a higher expected fitness.

values of food sources vary in quantity and quality. For example, honeydew has been found to be poorer quality compared with floral nectar with regard to lifetime extension (Leius 1961, Wäckers and Swaans 1993, Gilbert and Jervis 1998, Wäckers 1999, Hougardy and Gregoire 2000), and in one study honeydew did not extend life span at all (Avidov et al. 1970). Floral nectar is often high in quality but can vary considerably in quantity, depending on the time of the day, climate and competition with other nectar foragers (Baker and Baker 1983, Kevan and Baker 1999). In addition, the mortality risk during food searching may be elevated because predators are also attracted to sugar sources (Jervis 1990). What is best for a female parasitoid is likely to depend on external conditions such as predation risk and weather conditions as well as her internal states such as age, egg load and energy reserves, the costs of foraging and the availability of resources (Collier et al. 1994, Murdoch et al. 1997, Weisser et al. 1997, Heimpel et al. 1998).

Stochastic dynamic programming (SDP) models are ideal for predicting state dependent strategies (Bellman 1957, Clark and Mangel 2000). Sirot and Bernstein (1996) used this modelling technique to predict optimal time allocation in host- and sugar foraging parasitoids early in life (Figure 2). Their model assumes the occurrence of two patches, a host patch and a food patch. Moving between patches incurs significant metabolic costs, and remaining on either patch decrements energy reserves only by one unit. On the host patch females parasitize

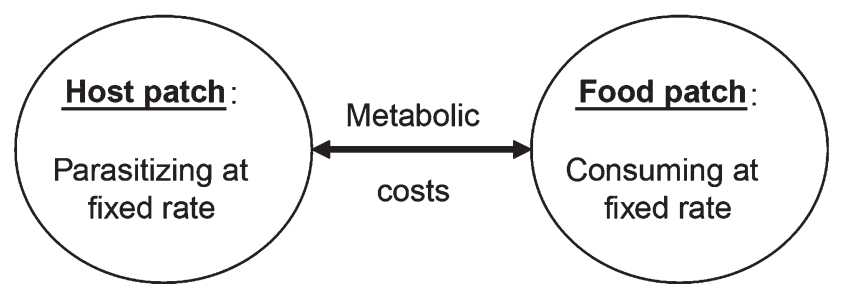

Figure 2. Illustration of Sirot and Bernstein's optimal time allocation model (1996).

hosts at a given rate; on the food patch they first search for food, but once they find a food they consume it at a given rate. By assuming constant feeding or parasitism rates the model ignores the effect of short term variation in these rates. Because variation in the time to find hosts influences parasitoid's lifetime reproductive success (Houston et al. 1992) it is possible that variation in parasitism rate also shapes parasitoid behavior. For example, a female close to starvation may benefit from staying in a host patch and receiving a guaranteed small fitness return, if finding food is uncertain. The trade-off might shift in favor of searching for food if the fitness reward in the host patch is uncertain as well.

Envisage the parasitoid, Cotesia rubecula, searching for caterpillar hosts (Pieris rapae (L.), Lepidoptera: Pieridae) among cruciferous crop plants (Figure 3). She finds a host by responding to volatiles (synomones) elicited by plants as a response to caterpillar feeding damage (Sabelis and de Jong 1988, Mattiacci et al. 1994, Horikoshi et al. 1997). In her search for hosts she flies to different leaves of the same plant and neighboring plants, which consumes a large amount of energy because flying is one of the most energy-demanding processes in insects (Wigglesworth 1972, Ellington et al. 1990). If her energy reserves drop below some threshold level,

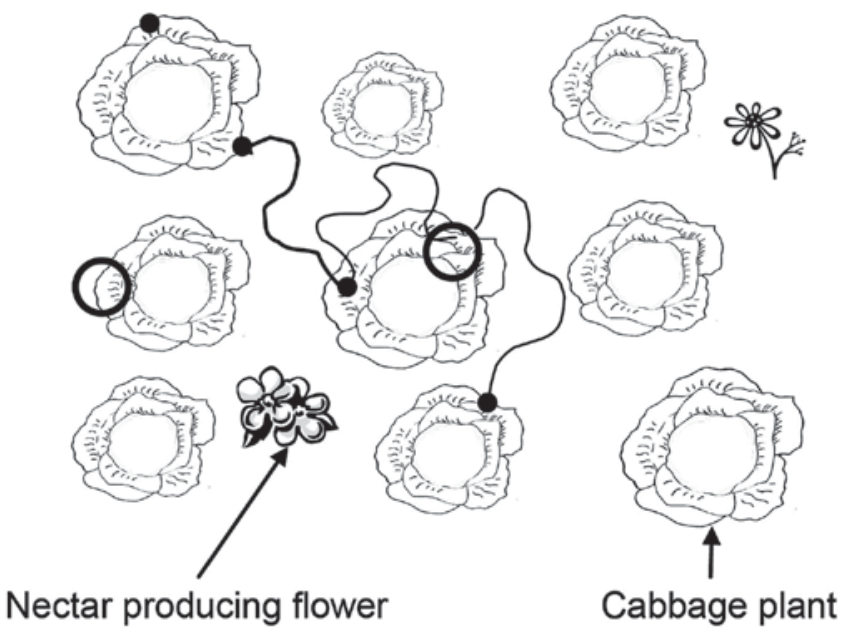

Figure 3. Illustration of a female parasitoid foraging for hosts and food among cabbage plants. The black dots indicate host patches, the circles honeydew patches, and the curvy line a typical flight of a female parasitoid. 
she switches from responding to host cues to responding to food cues associated with honeydew or flowering (weed) plants growing between the cruciferous plants. Once she finds a food source, it is by no means certain that she can feed to satiation because of the high variability in food reward, and she might require several food encounters to fill her crop, especially because travelling between food sources consumes energy as well. Would the predictions of a model mimicking a more realistic scenario like this differ from those generated by Sirot and Bernstein's model (1996)?

The first step in translating more realistic scenarios as this one into a patch model is to define what constitutes a patch. Let assume a patch is a plant leaf or flower (Vos et al. 1998), then C. rubecula's foraging environment can be described as many randomly distributed food and host patches. In the field, usually a cabbage plant contains between zero and two $P$. rapae larvae (Harcourt 1961, Kobayashi 1966, Jones 1977). Because P. rapae larvae tend to avoid each other (pers. obs.) the majority of host patches contain either zero or one host. Envisioning a multi-patch environment requires a structurally different modelling approach than Sirot and Bernstein's two patch model (1996).

The feeding frequency required to avoid starvation will depend on the rate of energy depletion through maintenance and movement. Siekmann (2002) quantified the energy expenditure of host searching for C. rubecula in wind tunnel experiments. According to her experiments, wasps confined in a small cage, where their activity was restricted to walking and small flights (such as within-plant searching), use up $24 \%$ of the female's initial carbohydrate reserves over the course of one day, but females that additionally are forced to fly in a wind tunnel $\left(40-50 \mathrm{~cm} \mathrm{~s}^{-1}\right)$ for a total of 9 min use up twice as much carbohydrate. This example demonstrates the potential significance of carbohydrate consumption for parasitoid fitness. It is thus not surprising that in the field and laboratory parasitoids are attracted to flowers (Van Emden 1963, Shahjahan 1974, Maingay et al. 1991, Jervis et al. 1993), and that in the laboratory hungry parasitoids respond to specific food cues such as odors or colors (Lewis and Takasu 1990, Wäckers 1994, Siekmann 2002). Recent research documents significant carbohydrate uptake of parasitoids in the wild (Venturia canescens [Gravennhorst], Casas et al. 2003).

We constructed a SDP model that explicitly incorporates the high energy expenditure of host and food foraging, short-term variation in search times, and a probabilistic distribution of food rewards. We envisage a multi-patch environment where food and host patches are separated in space at fine scales. The value of constructing a model mimicking more realistic scenarios is to make it relevant to wider range of biologists. Initially we parameterized the model using empirical data from Cotesia rubecula (Marshall) (Hymenoptera: Bracon- idae). We used then a sensitivity analysis to explore a similar parameter space as Sirot and Bernstein (1996), so we consider that the conclusions of our model to be applicable to a wide range of parasitoid species. The most interesting prediction of this model is that parasitoids should always search for food if they are close to starvation, which is consistent with empirical findings (Siekmann 2002, chapter 3). In contrast, Sirot and Bernstein's model suggests parasitoids should never search for food if food availability is low.

\section{The biological system}

Cotesia rubecula females are solitary parasitoid wasps that lay single eggs inside their hosts. After hatching, a wasp larva feeds internally on the host's tissue and kills the host at the end of larval development. Only one egg can develop within a single host (Godfray 1987). The hosts are larvae of the cabbage butterfly, $P$. rapae, which feed on cruciferous plants. Female wasps readily attack any hosts they encounter (M. Keller, pers. obs.); afterwards they usually fly or walk away from the oviposition site, which has been suggested to prevent laying more than one egg in a single host (self-superparasitism) (Wiskerke and Vet 1994).

Cotesia rubecula is a synovigenic species (Heimpel et al. 1997): females eclose with approximately 30 mature eggs, and without an opportunity to oviposit this number increases to 75 after two days (Nealis 1990). Despite the high egg complement females oviposit only 10 eggs per day if hosts are abundant, because they spend a long time examining host feeding damage, and require a long time to recover after host attack, especially if hosts are large (i.e. 3rd instar) (Nealis 1990). As the maximum life expectancy of $C$. rubecula in large field cages $(3 \times 3 \times 1.7$ $\mathrm{m}$ ) is 12 days (median $=2.5 \mathrm{~d}$, Siekmann 2002), it is unlikely that females run out of eggs before they die.

Carbohydrate uptake greatly increases life expectancy of C. rubecula; just a single sugar meal can double female survival (Siekmann et al. 2001). How often females need to consume food to prevent starvation depends to a large extend on the amount and carbohydrate concentration of available food. Assuming each food source contains plenty of nectar and C. rubecula can always fill up her crop $(1 \mu \mathrm{l})$ then she needs to find food once per day if the sugar concentration is $25 \%$, but only every $2-3$ days if sugar concentration is $50 \%$ (Siekmann et al. 2001). However, it is unlikely that females will be able to feed to saturation on a single food source. For example, the daily nectar secretion of Brassica flowers varies between 0.7-6 $\mu$ l with a sugar concentration of 10-60\% (Mohr and Jay 1990, Pierre et al. 1999), and the sugar concentration of aphid honeydew varies between 0.4-10\% (Auclair 1963, Engel et al. 2001, Fischer et al. 2002). 


\section{The model}

A stochastic dynamic programming (SDP) model has three components: the state variables and their dynamics, the set of decisions, and the pay-off function. (Bellman 1957, Clark and Mangel 2000). SDP models start at the end of an individual's life (T) and then work backwards in time, calculating for each combination of states the behavior that results in the highest fitness. We set the terminal fitness function to 0 because no fitness can be accrued after death. Here we are concerned with the stationary solutions of this process, i.e. when parasitoid's age $\ll$ T (Sirot and Bernstein 1996, Clark and Mangel 2000).

The state variable in this model is a female's energy (carbohydrate) reserves $(x)$, with the upper boundary, C, determined by females' crop capacity. The size of energy reserves changes as a function of food consumption (E), and searching activity (a). Parasitoids starve to death if their energy state drops below a minimum threshold, c. At any point in time females have two behavioral choices: searching for hosts or searching for food. The ultimate pay-off function for these decisions is lifetime reproductive success. In the model we used time-steps of one hour, assuming parasitoids are active for $10 \mathrm{~h}$ per day, and the maximum life expectancy of the parasitoid is denoted with T. A shorter daily activity time would translate to a reduction in $\mathrm{T}$ (in time units) and would not change parasitoid's foraging behavior early in life.

During each time interval $t$, female parasitoids die with probability $\mu_{h}$ while searching for hosts or $\mu_{f}$ while searching for food. In addition, parasitoids die if energy levels drop below the starvation threshold, c. If a female survives, she encounters a host patch or food source with a probability of $\lambda_{h}$ or $\lambda_{f}$, respectively. Finding a host patch yields an immediate fitness gain of 1 . This model is concerned with parasitoids foraging among patches at a small scale, so that most host patches (i.e. cabbage leaf) contain either zero or one $P$. rapae larva. Because C. rubecula usually lays a single egg into a host, the gain in fitness can be interpreted as being one egg. Then, the total number of eggs laid by a female during her lifetime is used as fitness currency. Alternatively, the fitness gain could be interpreted as being one clutch of eggs of average clutch size, in which case the fitness currency would be the number of clutches oviposited over the course of a female's life.

The pay-off for searching for hosts $\left(s_{h}\right)$ or food $\left(s_{f}\right)$ is calculated as:

$$
\begin{aligned}
\mathrm{s}_{\mathrm{h}}= & \left(1-\mu_{\mathrm{h}}\right)\left[\lambda_{\mathrm{h}}(\mathrm{F}(\mathrm{x}-\mathrm{a}, \mathrm{t}+1, \mathrm{~T})\right. \\
& \left.+\left(1-\lambda_{\mathrm{h}}\right) \mathrm{F}(\mathrm{x}-\mathrm{a}, \mathrm{t}+1, \mathrm{~T})\right], \quad \text { and } \\
\mathrm{s}_{\mathrm{f}}= & \left(1-\mu_{\mathrm{f}}\right)\left[\lambda_{\mathrm{f}} \sum_{\mathrm{i}} \mathrm{p}_{\mathrm{i}} \mathrm{F}\left(\mathrm{x}-\mathrm{a}+\mathrm{E}_{\mathrm{i}^{\prime}} \mathrm{t}+1, \mathrm{~T}\right)\right. \\
& \left.+\left(1-\lambda_{\mathrm{f}}\right) \mathrm{F}(\mathrm{x}-\mathrm{a}, \mathrm{t}+1, \mathrm{~T})\right]
\end{aligned}
$$

where $\mathrm{p}_{\mathrm{i}}$ is the probability that the nectar reward is $\mathrm{E}_{\mathrm{i}}$. The nectar reward is normally distributed with one standard deviation around the mean, $\bar{E}$. Here we use a pay-off function that includes four E-values below and above $\bar{E}\left(p_{-4}, p_{4}=0.0002, p_{-3}, p_{3}=0.006, p_{-2}, p_{2}=0.061\right.$, $\left.\mathrm{p}_{-1}, \mathrm{p}_{1}=0.242, \mathrm{p}_{0}=0.382\right)$. The highest and smallest value of $\mathrm{p}_{\mathrm{i}}$ include the probabilities below and above, so that $\sum_{\mathrm{i}} \mathrm{p}_{\mathrm{i}}=1$.

The dynamic programming equation is as follows:

$$
F(x, t, T)=\max \left[s_{h}, s_{f}\right] \text {, where } F(x, T, T)=0
$$

\section{Model assumptions}

\section{Energy expenditure of host and food foraging}

This model assumes that food and single hosts occur in different locations (microhabitats) that are randomly distributed within the same forging area (e.g. cabbage field). So, the probability of encountering a host of food patch is independent of a parasitoid's location. At the beginning of each time-step, a female parasitoid decides whether to search for a host or a food; her decision depends only on her energy reserves and age. Independent of her decision, her energy reserves are reduced by a. The total energy expenditure of locating a host or food patch depends on the probability of finding a host $\left(\lambda_{h}\right)$ or a food $\left(\lambda_{f}\right)$ patch. Thus, the predicted optimal time allocation takes into account that the energy expenditure necessary to find hosts or food is a geometrically distributed random variable. For example, assume a female's encounter sequence is "hosthost-nothing-food $\left(E_{i}\right)^{\prime \prime}$, then her total energy expenditure is $4 \mathrm{a}$, her energy reserves increased by $\mathrm{E}_{\mathrm{i}}$, and her fitness increased by 2 .

\section{Superparasitism}

Our model ignores superparasitism. We assume a system with a small number of parasitoids, in which the chances of encountering parasitized hosts are small, and that C. rubecula cannot distinguish parasitized from unparasitized hosts (Tenhumberg et al. 2001). At any given host density, superparasitism will then occur at rate $\mathrm{z}$ in which case the average fitness gain of each oviposition would be $1-\mathrm{z}$. Such scaling does not affect model predictions.

\section{No egg-limitation}

This model assumes that parasitoid fitness is determined by host availability and life expectancy (time-limited species). This assumes that at no point in time parasitoids are egg-limited, thus variation in egg load has no fitness consequences and the effect of carbohydrates on egg load can be ignored. For the same reason the timing 
of egg maturation can be ignored as long as there are always sufficient eggs available for oviposition. Thus the model is applicable to strictly pro-ovigenic species in which females emerge with their full egg complement as well as synovigenic species that emerge with a high proportion of mature egg complement or mature the remaining eggs during early adult life (Jervis et al. 2001).

\section{Estimation of basic parameters}

We parameterized the model with data for C. rubecula. Most of the baseline estimates are based on Siekmann (2002) and are listed in Table 1. In the model we assume each time-step is one hour, and a foraging day consists of $10 \mathrm{~h}$ of foraging time. This means that, C. rubecula females can parasitize a maximum of 10 hosts per day, which is consistent with empirical findings by Nealis (1990). If given the opportunity, females will parasitize more than one host per hour, but over the course of a single day they will not encounter more than 10 hosts because it takes them considerable time to find hosts in the field.

The maximum life expectancy of model parasitoids is $T=120$, which is equivalent to 12 days. This is the maximum longevity observed for $C$. rubecula in large field cages (Siekmann 2002), but in smaller rearing units they can live up to 40 days (Wäckers and Swaans 1993). The exact value of $T$ is relatively unimportant because the results focus on the behavior in the early adulthood when a female's decision is independent of age. In general, parasitoid behavior was independent of age for $t$ $<50$ time steps or 5 days. Towards the end of her life females search for food less and less frequently until they exclusively search for hosts (results not shown). This is because as $t$ is approaching $T$, the effect of feeding on extending life expectancy diminishes. It is well known that parasitoids change their foraging behavior when their life expectancy is short (Roitberg et al. 1992, 1993, Fletcher et al. 1994). Following Sirot and Bernstein (1996), this paper focuses on the trade-off between cur- rent and future reproduction, which is most relevant early on in a parasitoid adult's life.

We assumed that the mortality risk while foraging for food is higher than for hosts because nectar and honeydew frequently attract predators (Morse 1986, Maingay et al. 1991). In the model we examined a range of mortality risks of $0.1,0.01$ and 0.001 per hour. For comparison, the predation risk of the parasitoid Aphytis aonidiae (Mercet) (Hymenoptera: Aphelinidae) foraging for scale insects in the field is 0.06 per hour (Heimpel et al. 1997). In the model, we define the energy expenditure during each time-step is being one energy unit, and the starvation threshold 6 energy units (Table 1). According to Siekmann (2002) females emerge with $52 \mu \mathrm{g}$ carbohydrates and can store a maximum of $104 \mu \mathrm{g}$ carbohydrates. Assuming one energy unit is equivalent to $2.17 \mu \mathrm{g}$ carbohydrates, this translates to 24 energy units and 48 energy units respectively. Hence, females that do not consume any food will die after 18 time steps or 1.8 days, which is only slightly shorter (three time steps) than reported by Siekmann (2002).

\section{Results}

We present the optimal time allocation only for energy values between 6 (= starvation threshold, c) and 48 (= female crop capacity, C) units because dead individuals cannot exhibit any behavior. We then scale the remaining 42 units, so that 0 indicates the starvation threshold and 1 the maximum energy value. For example, an energy value of 0.05 indicates that energy reserves are $5 \%$ above starvation threshold.

The probability of finding hosts does not noticeably influence the optimal time allocation of parasitoids (results are not shown). The only way for parasitoids to gain fitness is by searching for hosts. Thus parasitoids do not have any choice but to search for hosts without consideration of how long it takes to find hosts. In con-

Table 1. Baseline parameters used in the SDP model.

\begin{tabular}{llcc}
\hline Parameter & Description & Units & Link to real wasps \\
\hline $\mathrm{T}$ & maximum life expectancy & 120 & 12 days* $^{*}$ \\
$\mathrm{x}_{0}$ & energy reserves at emergence & 24 & $52 \mathrm{gg}^{*}$ \\
$\mathrm{C}$ & maximum energy reserves & 48 & $104 \mathrm{gg}^{*}$ \\
$\mathrm{C}$ & starvation threshold & 6 & $14 \mathrm{gg}^{*}$ \\
$\mathrm{E}$ & mean food reward & $12^{\ddagger}$ & $28 \mu \mathrm{g}$ \\
$\mathrm{A}$ & energy depletion while foraging & 1 & $1.8 \mu \mathrm{g}^{*}$ \\
$\lambda_{\mathrm{f}}$ & probability of encountering food & 0.8 & \\
$\lambda_{\mathrm{h}}$ & probability of encountering hosts & 0.8 & \\
$\mu_{\mathrm{f}}$ & mortality while searching for food & 0.1 & \\
$\mu_{\mathrm{h}}$ & mortality while searching for hosts & 0.01 & \\
\hline
\end{tabular}

* Siekmann 2002 .

$\ddagger$ If energy reserves are scaled between $c=0$ and $C=1$, a consumption of 12 energy units increases energy reserves by 0.29 ( $=$ $12 / 42)$ 
trast, the mortality risk while foraging for hosts and the details of food foraging such as energy expenditure while foraging, food availability and mortality risk all influence the optimal time allocation. Here we present each of these factors as a function of the probability of finding a food source, $\lambda_{\mathrm{f}}$ and we label the energy threshold below which parasitoids should initiate food searching as the "energy boundary".

\section{Probability of finding food, $\lambda_{\mathrm{f}}$}

There is an interesting non-linear relationship between the energy boundary and the probability of finding food, $\lambda_{\mathrm{f}}$ (Figs. 4 and 5). If travelling costs are low and mortality risks of both host and food foraging are small $\left(\mu_{h}=0.01, \mu_{f} \leq 0.01\right.$, dashed and dotted line in Figure $4 \mathrm{~A}$ ), then food foraging should start at medium to high energy values $(0.2-0.8)$, even if the probability of finding food, $\lambda_{\mathrm{f}}$, is very small. In all other cases, parasitoids should search for food at very low $\lambda_{\mathrm{f}}$-values only if they are close to starving (i.e. energy reserves $<0.05$ ). Above this threshold the energy boundary jumps to its maximum and then tends to decrease with increasing probability of finding food. With increasing probability of finding food, the expected search time decreases, and hence parasitoids should delay searching until energy reserves drop to a lower level. A non-linear response to food availability is also predicted by Sirot and Bernstein's model (1996). However, assuming a mortality risk of a magnitude that is likely to occur in nature $(=0.05$, Figure 1a Sirot and Bernstein 1996) their model predicts parasitoids should never search for food if the probability of finding a food patch drops below 0.3, which is in stark contrast to the results presented here.

\section{Energy expenditure during searching, a}

Higher travelling costs lead to generally higher energy boundaries and maximum values occur at higher probabilities of finding food ( $\lambda_{\mathrm{f}}$-values). Travelling cost determines the average amount of energy required to find hosts. Since with increasing travelling costs parasitoids rely more heavily on finding food in order to parasitize a sufficient number of hosts they switch to food foraging at higher energy levels provided there is a reasonable chance of finding food.

\section{Mortality risk of food foraging, $\mu_{\mathrm{f}}$}

If food searching is very risky $\left(\mu_{\mathrm{f}}=0.1\right)$, parasitoids should never search for food if energy reserves $>0.25$. In contrast, if the mortality risk while feeding is very low $\left(\mu_{\mathrm{f}}=0.001\right)$ parasitoids should start searching for food at much higher energy reserves, which can be as high as 0.8 if finding food is likely to take a long time $\left(\lambda_{f}\right.$ $=0.2$ ). As mortality risk during food foraging decreases, food foraging becomes relatively more beneficial and parasitoids start foraging for food at higher levels of energy reserves.

\section{Mortality risk of host foraging, $\mu_{h}$}

Generally, a high mortality risk lowers energy boundaries, and shifts their maxima towards higher probabilities of finding food, $\lambda_{\mathrm{f}}$. In order to accrue fitness parasitoids must forage for hosts. Increasing mortality risk during host foraging effectively reduces life expectancy of parasitoids because parasitoids do not have any choice but to search for hosts to obtain fitness, which in turn reduces the relative advantage of extending
Figure 4. Behavior of female parasitoids as a function of energy reserves, probability of finding food $\left(\lambda_{\mathrm{f}}\right)$, mortality risk while foraging for food $\left(\mu_{\mathrm{f}}\right)$ and hosts $\left(\mu_{\mathrm{h}}\right)$, and energy expenditure of foraging (a). The area above a curve indicates host searching is optimal, whereas the area below indicates food searching is optimal. The energy reserves are given as a proportion of the maximum amount of energy that can be stored by a parasitoid. Note that the lowest values for energy reserves $(=0.0)$ equals the starvation threshold, c. (A) C: $\mu_{\mathrm{h}}=0.01$, (B, D): $\mu_{\mathrm{h}}=0.1$, solid line: $\mu_{\mathrm{f}}=0.1$, broken line: $\mu_{\mathrm{f}}=0.01$, dotted line: $\mu_{\mathrm{f}}$ $=0.001$, upper graphs $(\mathrm{A}, \mathrm{B}): \mathrm{a}=1$, bottom graphs $(C, D): a=2$. Values of basic parameters are listed in Table 1 .
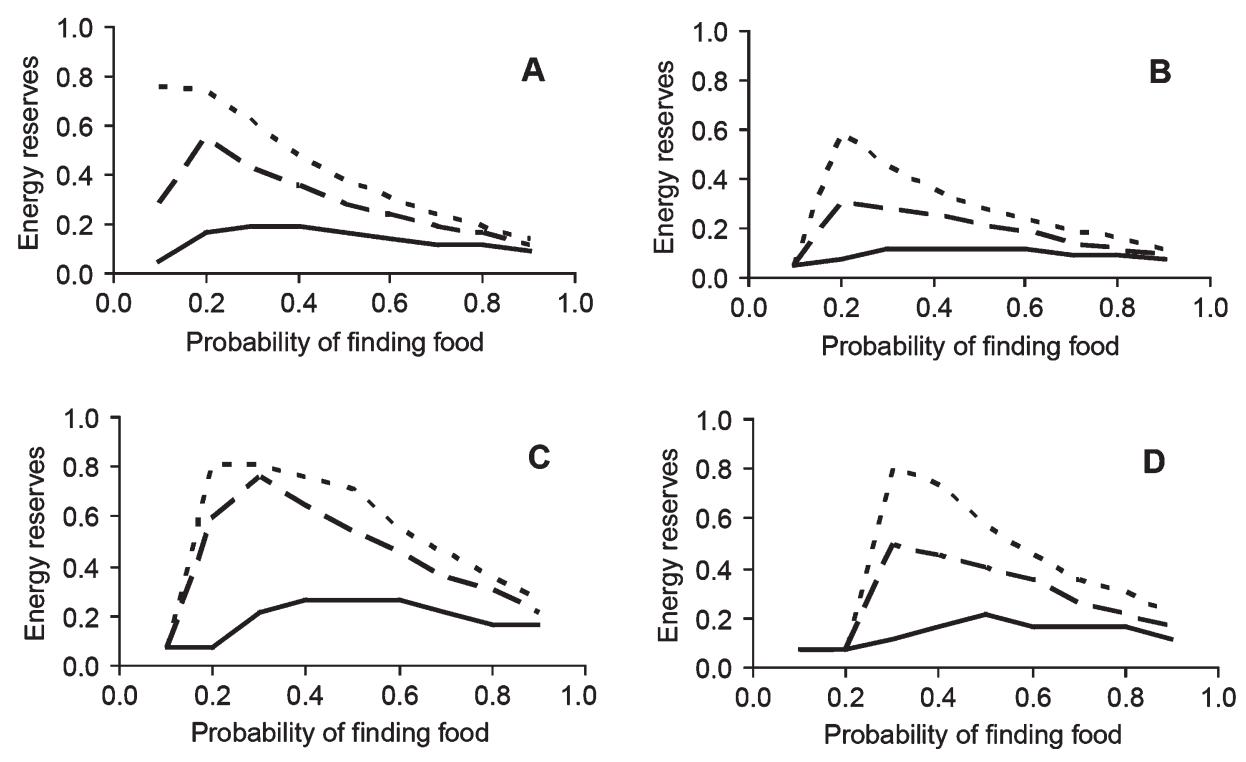


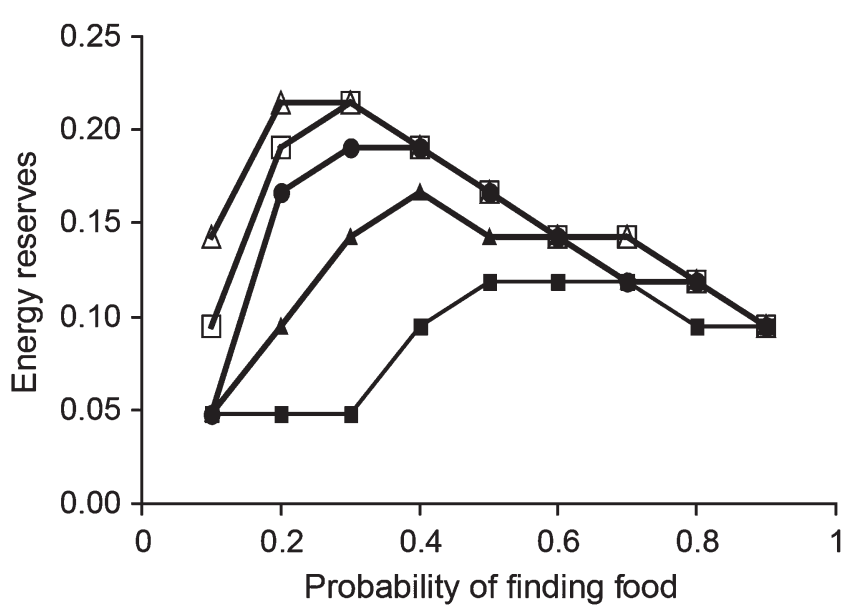

Figure 5. Optimal foraging behavior as a function of food availability and energy reserves. The area above a curve indicates host searching is optimal, whereas the area below indicates food searching is optimal. The energy reserves are given as a proportion of the maximum amount of energy that can be stored by a parasitoid. Symbols indicate different expected energy rewards that can be consumed if a food source is found: $0.1(\bullet), 0.2(\boldsymbol{\Delta}), 0.3(\bullet), 0.4(\square)$ and $0.5(\Delta)$. A value of 0.1 means that on average the amount of carbohydrates on each food source is equivalent to $10 \%$ of a parasitoid's maximum energy reserves and is equivalent to $\overline{\mathrm{E}}=4$. Note that the lowest values for energy reserves $(=0.0)$ equals the starvation threshold, c. Values of basic parameters are listed in Table 1.

life through feeding. This result is consistent with the effect of increasing background mortality rate predicted by Sirot and Bernstein's model (1996).

\section{Food reward, $\overline{\mathrm{E}}$}

In general, maximum energy boundaries are higher with increasing average reward per food source, $\overline{\mathrm{E}}$. The effect of increasing food reward decreases at higher values of $\overline{\mathrm{E}}$, and the predictions for $\overline{\mathrm{E}}>20$ energy units or $50 \%$ of a parasitoid's maximum energy reserves are virtually identical (results not shown). The influence of food reward is strongest at lower probability of finding food and is almost insignificant if food sources are frequently encountered. Food foraging is highly beneficial if parasitoids can expect a high reward from food sources. Consequently parasitoids should start searching for food at higher energy levels, even if the probability of finding food quickly is small.

\section{Random search}

Using the same programming technique as before, we calculated the expected fitness of newly emerged wasps $(x=24, t=0)$ that always search for hosts, but the probability of encountering food opportunistically $\left(\lambda_{\mathrm{r}}\right)$ is lower compared to wasps that actively engage in food searching $\left(\lambda_{\mathrm{f}}\right.$ in Equation 1). If this fitness value is higher than that calculated for wasps that use an active search strategy, then the evolution of active search would not be favored. By varying $\lambda_{\mathrm{r}}$, we can identify the advantage active searching would have to confer before an active search strategy is advantageous. The dynamic programming equation is

$$
\begin{aligned}
\mathrm{F}(\mathrm{x}, \mathrm{t}, \mathrm{T})= & \left(1-\mu_{\mathrm{h}}\right)\left\{\lambda_{\mathrm{h}}\left(1-\lambda_{\mathrm{r}}\right)(\mathrm{F}(\mathrm{x}+\mathrm{a}, \mathrm{t}+1, \mathrm{~T})+1)\right. \\
& +\lambda_{\mathrm{h}}\left(\lambda_{\mathrm{r}} \sum_{\mathrm{i}} \mathrm{p}_{\mathrm{i}} \mathrm{F}\left(\mathrm{x}-\mathrm{a}+\mathrm{E}_{\mathrm{i}^{\prime}} \mathrm{t}+1, \mathrm{~T}\right)+1\right) \\
& +\left(1-\lambda_{\mathrm{h}}\right) \lambda_{\mathrm{r}} \sum_{\mathrm{i}} \mathrm{p}_{\mathrm{i}} \mathrm{F}\left(\mathrm{x}-\mathrm{a}+\mathrm{E}_{\mathrm{i}^{\prime}} \mathrm{t}+1, \mathrm{~T}\right) \\
& \left.+\left(1-\lambda_{\mathrm{h}}\right)\left(1-\lambda_{\mathrm{r}}\right) \mathrm{F}(\mathrm{x}-\mathrm{a}, \mathrm{t}+1, \mathrm{~T})\right\}
\end{aligned}
$$

Note, this formula does not include handling time during feeding, thus the estimated fitness is somewhat too high, and our estimate of conditions favoring the evolution of active search is conservative. On average, it is advantageous to allocate time between food and host searching if active search increases the probability of encountering a food source 20 times (i.e. $\lambda_{\mathrm{f}} / \lambda_{\mathrm{r}}>20$ ) at high mortality risk $\left(\mu_{h}=0.1\right)$ and 6 times at lower mortality $\left(\mu_{\mathrm{h}}=0.01\right)$.

\section{Discussion}

In this paper, we present a model predicting the optimal time allocation between searching for food and searching for hosts. Our model (hereafter the TSK model) includes more realism compared to the model proposed by Sirot and Bernstein (1996) (hereafter the SB model). The TSK model differs in incorporating uncertainty about the pay-offs to foraging and oviposition; the differences between both models is summarized in Table 2. In the SB model parasitoid behavior depend on their location, i.e. whether they are in a host patch or food patch, which makes comparisons between both models somewhat difficult. For example, in the SB model parasitoids on food patches need to decide how much energy to consume before leaving: with exception of the high mortality scenario, parasitoids on food patches always feed to satiation. In the TSK model parasitoids do not find patches with unlimited food and it is more likely that each food encounter results in only partial replenishment of their energy reserves. Consequently, our model never predicts food searching when energy levels exceed $85 \%$ of parasitoids maximum.

The most obvious difference in model predictions is that the SB model predicts that parasitoids should never search for food if $\lambda_{f}<0.3$, provided mortality risk is of a magnitude reported in the field (Heimpel et al. 1997), or 0.2 if mortality risk depends on energy state (Figure 1a, 1c, in Sirot and Bernstein 1996). In contrast, the TSK model predicts a threshold $(\approx 5 \%$ of maximum energy 
Table 2. Comparison between the model presented in this paper (TSK model) and the model proposed by Sirot and Bernstein (1996) (SB model).

TSK model
Parasitization success is specified by a probability distribution.
This means that it is never guaranteed that parasitoids will find
hosts before dying, especially if energy reserves are low.
number of offsprings for one period on the host patch.
Normally distributed energetic values of food resources that
usually allow only partial replenishment of energy reserves.
This means that parasitoids do not simply decide whether
they should invest energy and time to search for more food.
Energy expenditure per time-step is independent of
behavioral choice.
The probability of finding food or hosts determines the total
energy expenditure required to encountering food or hosts.
As a consequence the cost of foraging for food or hosts differs.
Mortality risk during food and host searching is different.
parasitoid's behavior.
Model predictions are independent of parasitoid location.

reserves) below which parasitoids should always search for food even if the probability of finding food $\left(\lambda_{f}\right)$ and the expected food reward $\bar{E}$ per food patch are small. This threshold exists even if the chances are extremely small, say $\lambda_{f}=0.0001$, parasitoids should still search for food if energy reserves reach this threshold (results not shown). Only if parasitoids do not expect any food in the environment $\left(\lambda_{f}=0\right)$ they will always search for hosts.

The TSK model suggests that females close to starvation it pays to favor food over host searching, which is consistent with empirical studies of $C$. rubecula, demonstrating that advanced starvation of females always results in searching the immediate environment for food (Siekmann 2002, chapter 3). Because females never parasitize at a fixed rate as in the SB model, it is by no means guaranteed that they will find host before starving to death. In addition, host searching incurs energy costs, which are not considered explicitly in the SB model. If we modify our model such that there are zero energy costs of host searching, the minimum energy threshold disappears (results not shown).

How important this new prediction is depends on how often parasitoids will drop to very low energy levels. According to our model we would only expect to find parasitoids with limited energy levels if food availability is low. Unfortunately, it is very difficult to study behavioral responses of parasitoids in the field as a function of different food availabilities because of their small size and problems involved with estimating food availability in the entire foraging area (e.g. nectar quantity of different flowers), and the entire range of possible food sources is usually unknown (Sisterson and Averill 2002). Casas et al. (2003) measured energy levels of wild Venturia canascens in an area with abundant honeydew produced by the generalist planthopper Metcalfa pruinosa (Say). The authors found energy levels of wild
SB model

Constant parasitization rates on host patch.

This means that each time step parasitoids on host patches receive a guaranteed fitness reward based on the expected

Constant consumption rates on food source.

This means females decide how much to consume before leaving.

Energy expenditure per time-step depends on behavioral choice.

Low energy depletion while on host or food patches, but high energy expenditure while moving between patches.

Constant background mortality risk independent of

Model predictions are depended on parasitoid location (host or food patch).

insects between individuals that had ad libitum access to food and freshly emerged wasps, which is consistent with our model predictions. There is empirical evidence that energy levels of parasitoids influence host searching behavior, such that fed wasps located hosts faster than unfed wasps indicating that starved wasps spend a larger proportion of time searching for food and feeding (Sisterson and Averill 2002).

If the distances between food sources and hosts are short why would parasitoids not adopt an opportunistic strategy, i.e. using resources as they encounter them at random? Key to this question is how much a parasitoid's efficiency in locating resources is improved by actively responding to resource cues. We believe that searching plants randomly for hosts is very inefficient. For example, $P$. rape butterflies fly randomly among brassicaceous plants and lay mostly one egg, but sometimes up to five eggs per plant (Kobayashi 1966). Without any cue it would take a long time for a wasp to find a single butterfly larva within cabbage fields. So it is very unlikely such parasitoids would search for hosts in a random fashion. The air around plants can contain $50+$ plant chemicals whose profile changes with damage, and parasitoids respond to these changed profiles (Schoonhoven et al. 1998). Parasitoids not only recognize plants infested with hosts but parasitoid females can even distinguish plants with different host densities (van Alphen and Vet 1986, Tenhumberg et al. 2001). The concentration of chemical cues influences which plants parasitoids choose for host searching and how long they search any particular plant before leaving (search time, Shaltiel and Ayal 1998).

However, it could be possible that parasitoids find hosts using chemical cues but find food randomly. Whether this behavior is adaptive depends on how much active search increases the probability of encoun- 
tering a food source, and is likely to vary between parasitoid species, with the food sources they can exploit, and due to environmental stochasticity. In scenarios such as the field study of Casas et al. (2003), where the only significant food source was honeydew excreted by a generalist planthopper species, we expect that the chances of finding food opportunistically would be rather small.

We parameterized the model with experimental data of $C$. rubecula. The advantage of applying a model to a specific species is that it becomes more meaningful and model evaluation is straightforward. Constructing a more realistic model increases its relevance to empirical biologists. We explored model predictions at a wide range of parameter combinations in order to increase the generality of the results. The only parameters we did not vary and remain specific to C. rubecula are the range of energy reserves (6-48 units), and life expectancy. Both of the parameters do not influence model predictions. This paper is only concerned with behavior early in an individual's life, which is independent of life expectancy, and choosing different minimum and maximum energy reserves would only scale up or down relative energy expenditure during searching, a. Instead of the range of energy values we varied a in our analysis. Therefore, we believe that the qualitative model predictions are applicable to many parasitoid species that are not egg-limited and do not feed on hosts; non-host-feeding spp. probably amount which amounts to several hundred thousand species (M. Jervis, pers. comm.).

Host-feeding or egg-limited parasitoids also need to trade off current for future reproduction (Figure 1), but the decisions are fundamentally different. Instead of ignoring host cues in favor of food cues (Lewis and Takasu 1990) host feeding parasitoids decide whether to use a particular host for feed or reproduction (Jervis and Kidd 1986, Heimpel and Collier 1996). Host feeding provides not only materials for oogenesis (Heimpel and Collier 1996) but ingested proteins and carbohydrates from host-feeding are also used for maintenance, thereby enabling females to spare lipids for reproduction (Giron et al. 2002, 2004, Casas et al. 2005). Thus host-feeding is an investment in future reproduction.

\section{Wider implications of food foraging}

Optimal time allocation between searching for food and hosts is important because it shapes parasitoid efficiency in restricting host populations twofold: (1) food searching reduces the instantaneous parasitism rate by diverting time from reproduction, and (2) carbohydrates can be used as flight fuel, thus increasing the range of host searching. Parasitoid efficiency is pertinent from an applied perspective because it determines the success of parasitoids as biocontrol agents (Leius 1960). In addition, food foraging behavior has been proposed to in- fluence population stability. For example, the ideal free distribution model of Sirot and Bernstein (1996) predicts that food searching has a stabilizing effect on the dynamics of host-parasitoid systems. Krivan and Sirot (1997) show that introducing optimal time sharing between searching for food and hosts in a host-parasitoid population model leads to persistence of otherwise nonpersistent dynamics. The underlying mechanism for increased stability in their model is a density dependent host depletion rate: parasitoids search solely for hosts if hosts are abundant, and search only for food if hosts are scares. Our TSK model expands the range of conditions under which parasitoids should search for food, and thus demonstrates that this stabilizing mechanism could be more widespread than previously thought.

\section{Acknowledgments}

We thank Andrew Tyre, Mark Jervis, Thomas Hoffmeister, Jerome Casas, and Larkin Powell for their comments of an earlier version of this manuscript. A contribution of the University of Nebraska Agricultural Research Division, Lincoln, NE 68583. Journal Series No. 14770.

\section{References}

Auclair, J. L. 1963. Aphid feeding and nutrition. Annu. Rev. Entomol. 8: 439-490.

Avidov, Z., Balshin, M. and Gerson, U. 1970. Studies on Aphytis coheni, a parasite of California red scale, Aonidiella aurantii, in Israel. Entomophaga 15: 191-207.

Baker, H. G. and Baker, I. 1983. A brief historical review of the chemistry of floral nectar. In: Bentley, B. and Elias, T. (eds), The biology of nectaries. Columbia University Press, pp. 126-153.

Bellman, R. 1957. Dynamic programming. Princeton University Press.

Casas, J., Driessen, G., Mandon, N. et al. 2003. Energy dynamics in a parasitoid foraging in the wild. J. Anim. Ecol. 72: 691-697.

Casas, J., Pincebourde, S., Mandon, N. et al. 2005. Lifetime nutrient dynamics reveal simultaneous capital and income breeding in a parasitoid. Ecology 86: 545-554.

Clark, C. W. and Mangel, M. 2000. Dynamic state variable models in ecology: Methods and applications. Oxford University Press.

Collier, T. R., Murdoch, W. W. and Nisbet, R. M. 1994. Egg load and the decision to host-feed in the parasitoid, Aphytis melinus. J. Anim. Ecol. 63: 299-306.

Ellington, C. P., Machin, K. E. and Casey, T. M. 1990. Oxygen consumption of bumblebees in forward flight. Nature 347: 472-473.

Engel, V., Fischer, M. K., Wackers, F. L. et al. 2001. Interactions between extrafloral nectaries, aphids and ants: Are there competition effects between plant and homopteran sugar sources? Oecologia 129: 577-584.

Fischer, J., Volkl, W., Schopf, R. et al. 2002. Age-specific patterns in honeydew production and honeydew composition in the aphid Metopeurum fuscoviride: Implications for antattendance. J. Insect Physiol. 48: 319- 326. 
Fletcher, J. P., Hughes, J. P. and Harvey, I. F. 1994. Life expectancy and egg load affect oviposition decisions of a solitary parasitoid. Proc. R. Soc. B 258: 163-167.

Gilbert, F. and Jervis, M. A. 1998. Functional, evolutionary and ecological aspects of feeding-related mouthpart specializations in parasitoid flies. Biol. J. Linn. Soc. 63: 495-535.

Giron, D., Pincebourde, S. and Casas, J. 2004. Lifetime gains of host-feeding in a synovigenic parasitic wasp. Physiol. Entomol. 29: 436-442.

Giron, D., Rivero, A., Mandon, N. et al. 2002. The physiology of host feeding in parasitic wasps: Implications for survival. Funct. Ecol. 16: 750-757.

Godfray, H. C. J. 1987. The evolution of clutch size in parasitic wasps. Am. Nat. 129: 221-233.

Harcourt, D. G. 1961. Spatial pattern of the imported cabbageworm, Pieris rapae (L) (Lepidoptera: Pieridae), on cultivated cruciferae. Can. Entomol. 18: 945-952.

Heimpel, G. E. and Collier, T. R. 1996. The evolution of hostfeeding behavior in insect parasitoids. Biol. Rev. 71: 373-400.

Heimpel, G. E., Rosenheim, J. A. and Mangel, M. 1997. Predation on adult Aphytis parasitoids in the field. Oecologia 110: 346-352.

Heimpel, G. E., Mangel, M. and Rosenheim, J. A. 1998. Effects of time limitation and egg limitation on lifetime reproductive success of a parasitoid in the field. Am. Nat. 152: 273-289.

Horikoshi, M., Takabayashi, J., Yano, S. et al. 1997. Cotesia glomerata female wasps use fatty acids from plantherbivore complex in host searching. J. Chem. Ecol. 23: 1505-1515.

Hougardy, E. and Gregoire, J. C. 2000. Spruce stands provide natural food sources to adult hymenopteran parasitoids of bark beetles. Entomol. Exp. Appl. 96: 253-263.

Houston, A. I., McNamara, J. M. and Godfray, H. C. J. 1992. The effect of variability on host feeding and reproductive success in parasitoids. Bull. Math. Biol. 54: 465-476.

Jervis, M. A. 1990. Predation of Lissonota coracinus (Gmelin) (Hymenoptera: Ichneumonidae) by Dolichonabis limbatus (Dahlbom) (Hemiptera: Nabidae). Entomol. Gaz. 41: 231-233.

Jervis, M. A. 1998. Functional and evolutionary aspects of mouthpart structure in parasitoid wasps. Biol. J. Linn. Soc. 63: 461-493.

Jervis, M. A. and Kidd, N. A. C. 1986. Host-feeding strategies in hymenopteran parasitoids. Biol. Rev. 61: 395-434.

Jervis, M. A., Kidd, N. A. C. and Walton, M. 1992. A review of methods for determining dietary range in adult parasitoids. Entomophaga 37: 565-574.

Jervis, M. A., Kidd, N. A. C., Fitton, M. G. et al. 1993. Flowervisiting by hymenopteran parasitoids. J. Nat. Hist. 27: 67-105.

Jervis, M. A., Kidd, N. A. C. and Heimpel, G. E. 1996. Parasitoid adult feeding behavior and biocontrol-A review. Biocontrol News Inf 17: $11 \mathrm{~N}-26 \mathrm{~N}$.

Jervis, M. A., Heimpel, G. E., Ferns, P. N. et al. 2001. Life history strategies in parasitoid wasps: A comparative analysis of 'ovigeny.' J. Anim. Ecol. 70: 442-458.

Jones, R. E. 1977. Movement pattern and egg distribution in cabbage butterflies. J. Anim. Ecol. 46: 195- 212.

Kevan, P. G. and Baker, H. G. 1999. Insects on flowers. In: Huffaker, C. B. and Gutierrez, A. P. (eds), Ecological entomology. John Wiley \& Sons.
Kobayashi, S. 1966. Process generating the distribution pattern of eggs of the common cabbage butterfly Pieris rapae crucivora. Res. Popul. Ecol. 8: 51-61.

Krivan, V. and Sirot, E. 1997. Searching for food or hosts: the influence of parasitoids behavior on host-parasitoid dynamics. Theor. Popul. Biol. 51: 201-209.

Leius, K. 1960. Attractiveness of different foods and flowers to the adults of some hymenopterous parasites. Can. Zool. 92.

Leius, K. 1961. Influence of various foods on fecundity and longevity of adults of Scambus buolianae (Htg.) (Hymenoptera: Ichneumonidae). Can. Entomol. 93: 1079-1084.

Lewis, W. J. and Takasu, K. 1990. Use of learned odours by a parasitic wasp in accordance with host and food needs. Nature 348: 635-636.

Maingay, H. M., Bugg, R. L., Carlson, R. W. et al. 1991. Predatory and parasitic wasps (Hymenoptera) feeding at flowers on sweet fennel (Foeniculum vulgare Miller var. dulce Battandir \& Trabut, Apiaceae) and spearmint (Mentha spicata L., Lamiaceae) in Massachusetts. Biol. Agric. Hortic. 7: 363-383.

Mattiacci, L., Dicke, M. and Posthumus, M. A. 1994. Induction of parasitoid attracting synomone in Brussels-sprouts plants by feeding of Pieris-Brassicae larvae-role of mechanical damage and herbivore elicitor. J. Chem. Ecol. 20: 2229-2247.

Mohr, N. A. and Jay, S. C. 1990. Nectar production of selected cultivars of Brassica campestris and Brassica napus L. J. Agric. Res. 29: 95-100.

Morse, D. H. 1986. Predatory risk to insects foraging at flowers. Oikos 46: 223-228.

Murdoch, W. W., Briggs, C. J. and Nisbet, R. M. 1997. Dynamical effects of host size- and parasitoid state-dependent attacks by parasitoids. J. Anim. Ecol. 66: 542-556.

Nealis, V. G. 1990. Factors affecting the rate of attack by Cotesia rubecula (Hymenoptera: Braconidae). Ecol. Entomol. 15: 163-168.

Pierre, J., Mesquida, J., Marilleau, R. et al. 1999. Nectar secretion in winter oilseed rape, Brassica napus-quantitative and qualitative variability among 71 genotypes. Plant Breeding 118: 471-476.

Roitberg, B. D., Mangel, M., Lalonde, R. G. et al. 1992. Seasonal dynamic shifts in patch exploitation by parasitic wasps. Behav. Ecol. 3: 156-165.

Roitberg, B. D., Sitcom, J., Roitberg, C. A. et al. 1993. Life expectancy and reproduction. Nature 364: 108.

Sabelis, M. W. and de Jong, M. C. M. 1988. Should all plants recruit bodyguards? Conditions for a polymorphic ESS of synomone production in plants. Oikos 53: 247-252.

Schoonhoven, L. M., Jermy, T. and van Loon, J. J. A. 1998. Insect-plant biology: From physiology to evolution. Chapman and Hall

Shahjahan, M. 1974. Erigeron flowers as a food and attractive odour source for Peristenus pseudopallipes, a braconid parasitoid of the tarnished plant bug. Environ. Entomol. 3: 69-72.

Shaltiel, L. and Ayal, Y. 1998. The use of kairomones for foraging decisions by an aphid parasitoid in small host aggregations. Ecol. Entomol. 23: 319-329.

Siekmann, G. 2002. Food foraging in adult parasitoid Cotesia rubecula: How sugar sources contribute to survival and reproduction. Dept Appl. Mol. Ecol. Adelaide University, p. 148. 
Siekmann, G., Tenhumberg, B. and Keller, M. A. 2001. Feeding and survival in parasitic wasps: Sugar concentration and timing matter. Oikos 95: 425-430.

Sirot, E. and Bernstein, C. 1996. Time sharing between host searching and food searching in parasitoids: state-dependent optimal strategies. Behav. Ecol. 7: 189-194.

Sisterson, M. S. and Averill, A. L. 2002. Costs and benefits of food foraging for a braconid parasitoid. J. Insect Behav. 15: 571-588.

Tenhumberg, B., Keller, M. A., Tyre, A. J. et al. 2001. The effect of resource aggregation at different scales: Optimal foraging behavior of Cotesia rubecula . Am. Nat. 158: 505-518.

van Alphen, J. J. M. and Vet, L. E. M. 1986. An evolutionary approach to host finding and selection. In: Waage, J. K. and Greathead, D. (eds), Insect parasitoids. Academic Press, pp. 23-61.

Van Emden, H. F. 1963. Observations on the effect of flowers on the activity of parasitic Hymenoptera. Entomol. Monthly Mag. 98: 265-270.

Vos, M., Hemerik, L. and Vet Louise, E. M. 1998. Patch exploitation by the parasitoids Cotesia rubecula and Cotesia glomerata in multi-patch environments with different host distributions. J. Anim. Ecol. 67: 774-783.
Wäckers, F. L. 1994. The effect of food deprivation on the innate visual and olfactory preferences in the parasitoid Cotesia rubecula. J. Insect Physiol. 40: 641-649.

Wäckers, F. L. 1999. Gustatory response by the hymenopteran parasitoid Cotesia glomerata to a range of nectar and honeydew sugars. J. Chem. Ecol. 25: 2863-2877.

Wäckers, F. L. and Swaans, C. P. M. 1993. Finding floral nectar and honeydew in Cotesia rubecula: Random or directed. Proc. Exp. Appl. Entomol., N.E.V. Amsterdam 4: 67-72.

Weisser, W. W., Vo“ lkl, W. and Hassell, M. P. 1997. The importance of adverse weather conditions for behavior and population ecology of an aphid parasitoid. J. Anim. Ecol. 66: 386-400.

Wigglesworth, V. B. 1972. The principles of insect physiology. Chapman and Hall

Wiskerke, J. S. C. and Vet, L. E. M. 1994. Foraging for solitarily and gregariously feeding caterpillars: A comparison of two related parasitoid species (Hymenoptera: Braconidae). J. Insect Behav. 7: 585-603. 